\title{
Analysis of prognostic factors, including the incidence of second primary cancer, in patients with early stage laryngeal squamous cell carcinoma treated by radiation-based therapy
}

\author{
Kaname Sato ${ }^{1}$, Kenichiro Yabuki ${ }^{1}$, Daisuke Sano ${ }^{1}$, Yasuhiro Arai ${ }^{1}$, Yoshihiro Chiba ${ }^{1}$, Teruhiko Tanabe ${ }^{1}$, \\ Goshi Nishimura ${ }^{1}$, Masaharu Hata ${ }^{2}$, Nobuhiko Oridate ${ }^{1}$ \\ ${ }^{1}$ Department of Otorhinolaryngology, Head and Neck Surgery, Yokohama City University School of Medicine, Yokohama, Japan; ${ }^{2}$ Department of \\ Oncology, Yokohama City University Graduate School of Medicine, Yokohama, Japan \\ Contributions: (I) Conception and design: K Sato, K Yabuki, D Sano, Y Arai, Y Chiba, T Tanabe, G Nishimura, N Oridate; (II) Administrative support: \\ K Yabuki, N Oridate; (III) Provision of study materials or patients: All authors; (IV) Collection and assembly of data: K Yabuki, D Sano, N Oridate; (V) \\ Data analysis and interpretation: All authors; (VI) Manuscript writing: All authors; (VII) Final approval of manuscript: All authors. \\ Correspondence to: Kaname Sato, MD. Department of Otorhinolaryngology, Head and Neck Surgery, Yokohama City University School of Medicine, \\ 3-9 Fukuura, Kanazawa, Yokohama, 236-0004, Japan. Email: t176033e@yokohama-cu.ac.jp.
}

\begin{abstract}
Background: The purpose of this study was to elucidate the efficacy of concurrent chemotherapy and analyze prognostic factors in the radiation-based therapy for early stage laryngeal squamous cell carcinoma (ELSCC).
\end{abstract}

Methods: The records of 97 patients with ELSCC treated by radiation-based therapy from 2004 to 2016 were retrospectively reviewed. Eighty-one patients were treated with the combined-agent regimens during the treatment. Of the 81 patients, 58 were treated with S-1 regimen and 23 with other regimens. Clinical factors, such as concurrent chemotherapy, non-glottic subsite and the incidence of second primary cancer (SPC) were analyzed for their association with survival.

Results: From the analysis of all patients, the 5-year overall survival (OS) rates were found to be significantly poorer for patients with non-glottic cancer compared to those with glottic cancer $(\mathrm{P}<0.001)$, and non-glottic subsite was shown to be the only poor prognostic factor for OS by the multivariate analysis $(\mathrm{P}=0.006)$. SPC was responsible for two-thirds of all deaths. In the analysis of patients with stage II ELSCC, the 5-year disease-free survival (DFS) rates were significantly better for patients treated by concurrent chemoradiotherapy (CCRT) with S-1 compared to those treated by the other treatment methods, and a combination with the S-1 regimen was shown to be the only good prognostic factor for DFS by the multivariate analysis $(\mathrm{P}=0.015)$.

Conclusions: Non-glottic subsite and SPC were associated with worsened survival. CCRT with S-1 can be a useful treatment option for stage II ELSCC.

Keywords: Early stage laryngeal squamous cell carcinoma (ELSCC); concurrent chemoradiotherapy (CCRT); S-1; second primary cancer (SPC); survival

Submitted Apr 22, 2018. Accepted for publication Jun 13, 2018.

doi: $10.21037 /$ tcr.2018.06.15

View this article at: http://dx.doi.org/10.21037/tcr.2018.06.15

\section{Introduction}

Many patients with head and neck squamous cell carcinoma (HNSCC) are diagnosed at an advanced stage, whereas more than half of those with laryngeal cancer are diagnosed at an early stage $(1,2)$. Early-stage laryngeal squamous cell carcinoma (ELSCC), particularly the most common form arising in the glottis, is known to be curable. It does matter whether the treatment for ELSCC aims at preserving 
laryngeal function or not. According to the National Comprehensive Cancer Network (NCCN) Guidelines, partial laryngectomy, such as transoral laser microsurgery (TLM) and partial laryngectomy, and radiation therapy (RT) were recommend as appropriate treatment modalities for ELSCC (3). Previous articles comparing these two modalities reported that the treatment outcomes were generally similar $(4,5)$, whereas RT might afford better voice outcomes following treatment than TLM in patients with stage II cancer (5-7). In patients with residual or recurrence tumor, phonetic function is sacrificed in cases undergoing radical salvage surgery. Considering that the local control rate of stage II cancer remains unsatisfactory (8-11), we believe that the primary treatment strategy of stage II cancer needs to be enhanced.

Several articles reported that concurrent chemoradiotherapy (CCRT) with a low-intensity chemotherapy regimen was tolerable, and provided better local control than did RT alone (12-15). Among the various chemotherapeutic agents reported for use in concurrent chemotherapy, S-1 appeared to be effective (12-15). S-1 (Taiho Pharmaceutical Co., Ltd) is an orally available anticancer-drug consisting of tegafur, a prodrug of 5-fluorouracil, together with gimeracil and oteracil potassium. Gimeracil is an inhibitor of dihydropyrimidine dehydrogenase, which is responsible for 5-FU catabolism. Oteracil potassium is an inhibitor of 5 -FU phosphorylation in the gastrointestinal tract. This combination of agents is designed to enhance its anticancer effect and reduce gastrointestinal toxicity $(16,17)$. Its efficacy has been reported for a number of solid cancers including HNSCC $(12,13,15,18-22)$.

The incidence of second primary cancer (SPC) during the follow-up period after primary treatment in patients with HNSCC represents a considerable issue in terms of aggravating survival (23). Patients with HNSCC are reported to have high incidence of SPC, with an incidence of $2.6-4.0 \%$ per year (24-26).

In this study, we retrospectively reviewed survival outcomes, as well as the incidence of SPC, in patients with ELSCC treated by RT-based therapy. We also investigated the efficacy of irradiation with the $\mathrm{S}-1$ regimen as a treatment strategy for ELSCC.

\section{Methods}

\section{Patients}

We conducted a retrospective review of 128 patients with
ELSCC (T1-2N0M0) treated with curative intent in the Department of Otorhinolaryngology, Head and Neck Surgery, Yokohama City University Hospital, Japan, between April 2004 and June 2016. In this study, the stage of the tumor was determined on the basis of the clinical findings and classified according to the criteria of the Union for International Cancer Control (UICC), 7th edition, 2009. Among patients treated before 2009, only those corresponding to the above criteria were extracted. The pretreatment evaluation included physical examination, CT imaging, laryngoscopy, esophagogastroscopy, histological examination of the larynx, and ${ }^{18} \mathrm{~F}$-labeled fluorodeoxyglucose (FDG)-positron emission tomography (PET) or PET/CT imaging. Thirty-one patients had undergone surgery and were hence excluded from the study, resulting in the remaining 97 patients being included in the final analysis.

\section{Treatments}

RT was delivered in conventional fractions of 1.8 or 2.0 Gy to a total dose of 66.0-70.2 Gy, 5 days per week, using 4-6 MV X-rays. The median dose of radiation was 70.0 Gy (range, 60.0-70.2 Gy). The radiation fields were set up as follows: the primary tumor alone for glottic cancers; the primary tumor and, prophylactically, the bilateral cervical lymph node area (levels Ib-III) for supraglottic cancers; and the primary tumor and, prophylactically, the bilateral cervical lymph node area (levels Ib-IV) for subglottic cancers. Lateral opposed fields were used for glottic and supraglottic cancers. For subglottic cancers, radiation fields consisted of the lateral opposed fields to the upper neck and the anterior field to the lower neck. The cervical lymph node area received prophylactic doses of 39.6-45 Gy.

Several combined-agent regimens were used during the RT: the S-1 regimen (oral tegafur at 40 or $50 \mathrm{mg}$ twice daily for 2 weeks, followed by 1 week of rest) (12), uraciltegafur (UFT) regimen (oral UFT $300 \mathrm{mg}$ daily) (14), docetaxel (DOC) regimen $\left(12 \mathrm{mg} / \mathrm{m}^{2}\right.$ weekly) (27), carboplatin (CBDCA) plus UFT regimen (CBDCA at a dose of the area under the curve of 1.25 weekly and oral UFT $300 \mathrm{mg}$ daily) (14), cetuximab regimen (week 1: $400 \mathrm{mg} / \mathrm{m}^{2}$; subsequent weeks: $\left.250 \mathrm{mg} / \mathrm{m}^{2}\right)(28)$ and PFML regimen [cisplatin (CDDP) $\left(60 \mathrm{mg} / \mathrm{m}^{2}\right.$, Day 4$)$, 5 -fluorouracil $(5-\mathrm{FU})\left(600 \mathrm{mg} / \mathrm{m}^{2}\right.$ given over $24 \mathrm{~h}$ for 5 days, Days $1-5)$, methotrexate $\left(30 \mathrm{mg} / \mathrm{m}^{2}\right.$, Day 1$)$, and leucovorin (20 mg/m², Days 1-5), given every 4 weeks] (29). 


\section{Multiple primary cancer and SPC}

A multiple primary cancer was defined as another primary cancer of histologic origin different from the laryngeal cancer. "Synchronous" was defined as a multiple primary cancer developing within 6 months of ELSCC diagnosis. SPC was defined as another primary cancer detected 6 months after the laryngeal cancer was diagnosed.

\section{Evaluation}

At 2 months after the completion of RT, the response to the treatment was evaluated according to the Response Evaluation Criteria in Solid Tumors (30). For the followup, laryngoscopy was performed at least every 3 months, and imaging examinations, including CT and/or PET, were performed at least every 6 months in the survivors. Salvage surgery was considered when residual or recurrence was confirmed. Complications were assessed during treatment and at 4 weeks after treatment using the Common Terminology Criteria for Adverse Events v4.0. Written informed consent to participate in future retrospective studies was obtained from all study patients prior to treatment.

\section{Statistical analysis}

Statistical differences in predictive values were determined by Mann-Whitney's U test. Time-to-event statistics were calculated from the date of the first day of irradiation to the event of interest. Disease-free survival (DFS) was defined as the time to first relapse or death from any cause. Overall survival (OS) and DFS were estimated using the Kaplan-Meier method. The Wilcoxon logrank test was adopted to elucidate statistical differences in survival between the groups. For univariate and multivariate comparisons, Fisher's exact test and a Cox proportional hazards model were used, respectively. All statistical analyses were performed using EZR (Saitama Medical Center, Jichi Medical University, Saitama, Japan), which is a graphical user interface for $\mathrm{R}$ (The $\mathrm{R}$ Foundation for Statistical Computing, Vienna, Austria). All statistical tests were two-sided, with $\mathrm{P}$ values $<0.05$ considered significant. This study was approved by the International Review Board of Yokohama City University Hospital in accordance with the principles embodied in the Declaration of Helsinki.

\section{Results}

\section{Patient characteristics and treatment response}

Patient characteristics are summarized in Table 1. All 97

Table 1 Patient characteristics ( $\mathrm{n}=97)$

\begin{tabular}{|c|c|}
\hline Characteristic & Value \\
\hline \multicolumn{2}{|l|}{ Age (years) } \\
\hline Median & 68 \\
\hline Range & $51-84$ \\
\hline \multicolumn{2}{|l|}{ Sex, n (\%) } \\
\hline Male & $97(100.0)$ \\
\hline Female & 0 \\
\hline \multicolumn{2}{|l|}{ Subsite, n (\%) } \\
\hline Glottis & $88(90.7)$ \\
\hline Supraglottic & $6(6.2)$ \\
\hline Subglottic & $3(3.1)$ \\
\hline \multicolumn{2}{|l|}{ cT classification, n (\%) } \\
\hline $\mathrm{T} 1$ & $22(22.7)$ \\
\hline $\mathrm{T} 2$ & 75 (77.3) \\
\hline \multicolumn{2}{|c|}{ Combined-agent regimen, $\mathrm{n}(\%)$} \\
\hline None & $16(16.5)$ \\
\hline S-1 regimen & $58(59.8)$ \\
\hline UFT regimen & $11(11.3)$ \\
\hline DOC regimen & $5(5.2)$ \\
\hline CBDCA plus UFT regimen & $5(5.2)$ \\
\hline PFML regimen & $1(1.0)$ \\
\hline Cetuximab regimen & $1(1.0)$ \\
\hline \multicolumn{2}{|l|}{ RT dose (Gy) } \\
\hline Median & 70.0 \\
\hline Range & $66.0-70.2$ \\
\hline \multicolumn{2}{|l|}{ Treatment response, n (\%) } \\
\hline CR & $97(100.0)$ \\
\hline Non-CR & 0 \\
\hline \multicolumn{2}{|l|}{ Follow-up duration (months) } \\
\hline Median & 60.0 \\
\hline Range & $2.0-146.0$ \\
\hline
\end{tabular}

$\mathrm{RT}$, radiotherapy; S-1, tegafur-gimeracil-oteracil; UFT, tegafururacil; DOC, docetaxel; CBDCA, carboplatin; PFML, CDDP, 5-FU, methotrexate and leucovorin; $\mathrm{CR}$, complete response. 
Table 2 Treatment-related acute adverse events $(n=97)$

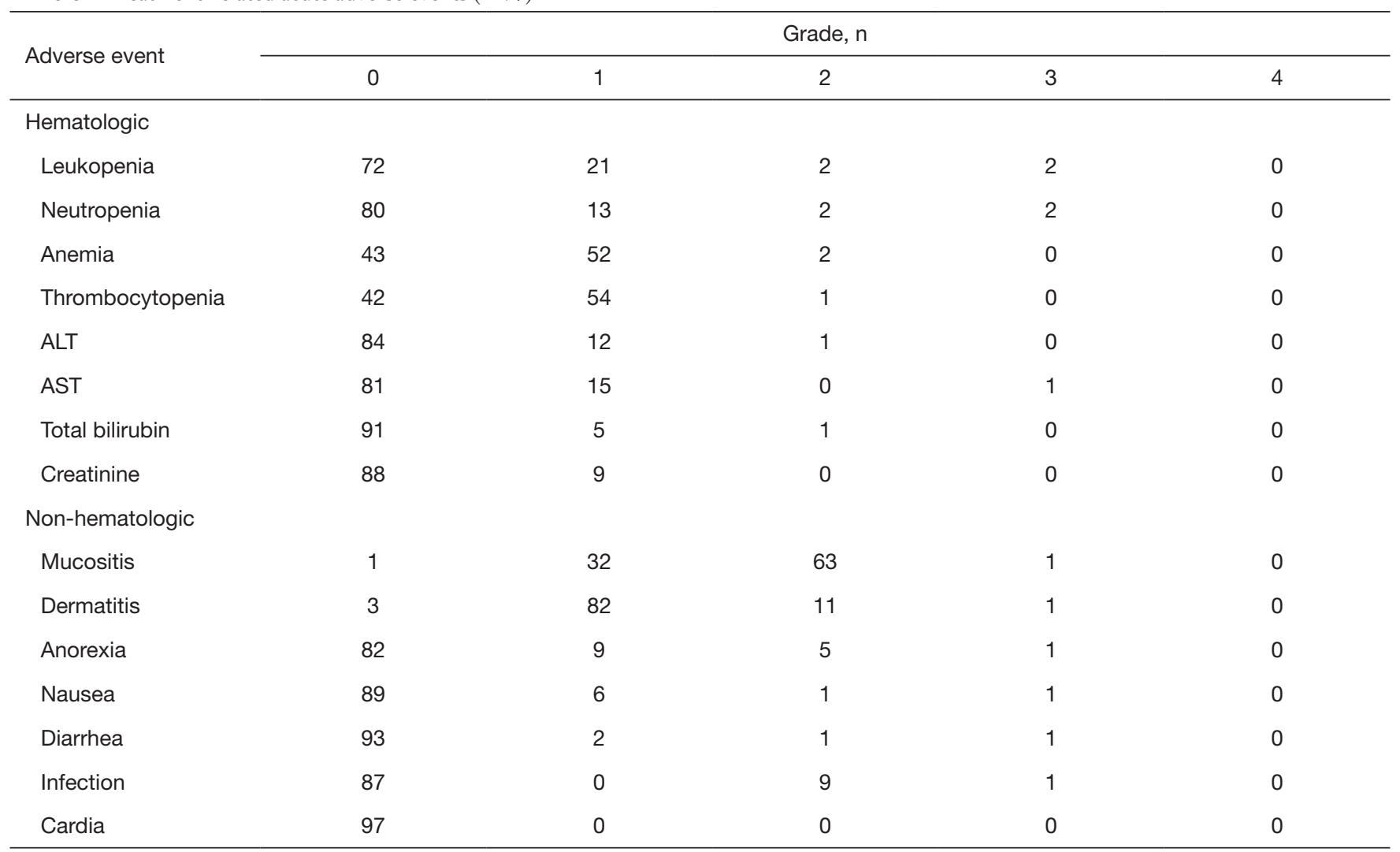

ALT, alanine aminotransferase; AST, aspartate aminotransferase.

study patients enrolled were male, with a median age of 68 (range, 51-84, mean 68.6) years. Eighty-eight patients $(90.7 \%)$ had a tumor in the glottic region, $6(6.2 \%)$ in the supraglottic region and $3(3.1 \%)$ in the subglottic region. With regard to tumor stage, 75 patients $(77.3 \%)$ presented with stage II cancer, and 22 (22.7\%) with stage I cancer. Eighty-one patients $(83.5 \%)$ were treated by CCRT or bioradiotherapy (BRT). As for the details of the combinedagent regimens, the S-1, UFT, DOC, CBDCA plus UFT, and cetuximab regimens were used in $58,11,5,5$, and 1 patients, respectively. One patient underwent the PFML regimen because of simultaneous treatment for esophageal carcinoma. The remaining 16 patients $(16.5 \%)$ were treated by RT alone based on tumor size and general condition. The median follow-up time was 60 months and a complete response $(\mathrm{CR})$ was confirmed in all patients after the primary treatment.

\section{Complications}

Acute adverse events for all patients are listed in Table 2.
Mucositis and dermatitis in the radiation field were the most commonly observed adverse events. No patients experienced any Grade 4 adverse event. Tube feeding was performed temporarily in only one patient who underwent the PFML regimen because of difficulties with oral intake due to Grade 3 mucositis, but no patient had a gastrostomy tube inserted or required a tracheostomy.

\section{Recurrence, SPC, and patient status}

The details of recurrence, incidence of SPC, and patient status are shown in Table 3. Recurrence was observed during follow-up in nine patients with stage II cancer. In terms of primary tumors before irradiation, seven patients presented with a glottic tumor and two with a supraglottic tumor. Local recurrence, regional recurrence, and distant metastasis were observed in seven, one, and one patient, respectively. The median interval from the completion of RT to recurrence was 51 months (range, 7-66 months). With regard to salvage surgery, total laryngectomy, TLM, and neck dissection were performed in 5, 2 and 1 patient, 
Table 3 Recurrence, second primary cancer and turning point ( $\mathrm{n}=97)$

\begin{tabular}{|c|c|}
\hline Characteristic & No. of patients (\%) \\
\hline \multicolumn{2}{|l|}{ Recurrence } \\
\hline Total & $9(9.3)$ \\
\hline Local & $7(77.8)$ \\
\hline Regional & $1(11.1)$ \\
\hline Distant & $1(11.1)$ \\
\hline \multicolumn{2}{|l|}{ Treatment after recurrence } \\
\hline \multicolumn{2}{|l|}{ Salvage surgery } \\
\hline $\mathrm{TL}$ & $5(55.6)$ \\
\hline TLM & $2(22.2)$ \\
\hline ND & $1(11.1)$ \\
\hline \multicolumn{2}{|l|}{ Palliative treatment } \\
\hline Anticancer agents & $1(11.1)$ \\
\hline \multicolumn{2}{|l|}{ Multiple primary cancer } \\
\hline Total & $38(39.2)$ \\
\hline Synchronous multiple primary cancer & $10 *(26.3)$ \\
\hline SPC & $11^{\star}(28.9)$ \\
\hline \multicolumn{2}{|l|}{ Site } \\
\hline Head and neck & $7^{\star}(18.4)$ \\
\hline Upper gastrointestinal cancer & $22^{*}(57.9)$ \\
\hline Lung cancer & $3^{*}(7.9)$ \\
\hline Other cancer & $15^{\star}(39.5)$ \\
\hline \multicolumn{2}{|l|}{ Patient status at final follow-up } \\
\hline Disease-free survival & $90(92.8)$ \\
\hline Tumor-bearing survival & $1(1.0)$ \\
\hline Death of recurrent of ELSCC & $1(1.0)$ \\
\hline Death of other causes & $5(5.2)$ \\
\hline Death of other cancer & $4(4.1)$ \\
\hline Death of heart disease & $1(1.0)$ \\
\hline
\end{tabular}

*There is some overlap. CR, complete response; TL, total laryngectomy; TLM, transoral laser microsurgery; ND, neck dissection; SPC, second primary cancer; ELSCC, early-stage laryngeal squamous cell carcinoma.

respectively. One patient underwent additional TLM due to local recurrence after salvage TLM. Systemic chemotherapy consisting of cetuximab, CDDP and 5-FU was performed for one patient with distant metastasis.

Multiple primary cancers were observed in 38 (39.2\%),
Table 4 Correlations between patient characteristics and incidence of $\operatorname{SPC}(\mathrm{n}=97)$.

\begin{tabular}{|c|c|c|c|}
\hline Characteristics & $\mathrm{N}(\%)$ & $\begin{array}{l}\text { Incidence of } \\
\text { SPC, n (\%) }\end{array}$ & $P$ value* \\
\hline Age & & & 0.356 \\
\hline$<69$ years & $49(50.5)$ & $4(8.2)$ & \\
\hline$\geq 69$ years & $48(49.5)$ & 7 (14.6) & \\
\hline Subsite & & & 0.063 \\
\hline Glottic & $88(90.7)$ & $8(9.1)$ & \\
\hline Non-glottic & $9(9.3)$ & $3(33.3)$ & \\
\hline cT classification & & & 0.264 \\
\hline T1 & $22(22.7)$ & $4(18.2)$ & \\
\hline T2 & $75(77.3)$ & $7(9.3)$ & \\
\hline Treatment modality & & & 0.202 \\
\hline CCRT & $81(83.5)$ & $11(13.6)$ & \\
\hline RT alone & $16(16.5)$ & $0(0)$ & \\
\hline Treatment modality & & & 0.751 \\
\hline CCRT with S-1 & $58(59.8)$ & $6(10.3)$ & \\
\hline Other & $39(40.2)$ & $5(12.8)$ & \\
\hline
\end{tabular}

*, Fisher's exact test. SPC, second primary cancer; CCRT, concurrent chemoradiotherapy; RT, radiation therapy; S-1, tegafur-gimeracil-oteracil.

and SPC was observed in 11 patients. As for the details of SPC, there were two head and neck cancers, two lung cancers, two colon cancers, one thyroid cancer, one esophageal cancer, one cutaneous malignancy, and one hematologic malignancy. The median interval from the diagnosis of ELSCC to the incidence of SPC was 48 months (range, 7-66 months).

Six patients died of the following causes: 1 of recurrence of ELSCC, 4 of SPC, and 1 of heart disease. The other 91 patients remained alive at the last follow-up (90 were recurrence free and one with recurrent disease).

\section{Correlation between the patient characteristics and incidence of SPC}

Details regarding the correlation between the patient characteristics and incidence of SPC are shown in Table 4. All SPCs were observed in the patients treated with CCRT. We compared the incidence of SPC by pretreatment factor and treatment strategy using univariate analysis, and no 
Table 5 Correlations between patient characteristics and prognostic factors $(\mathrm{n}=97)$.

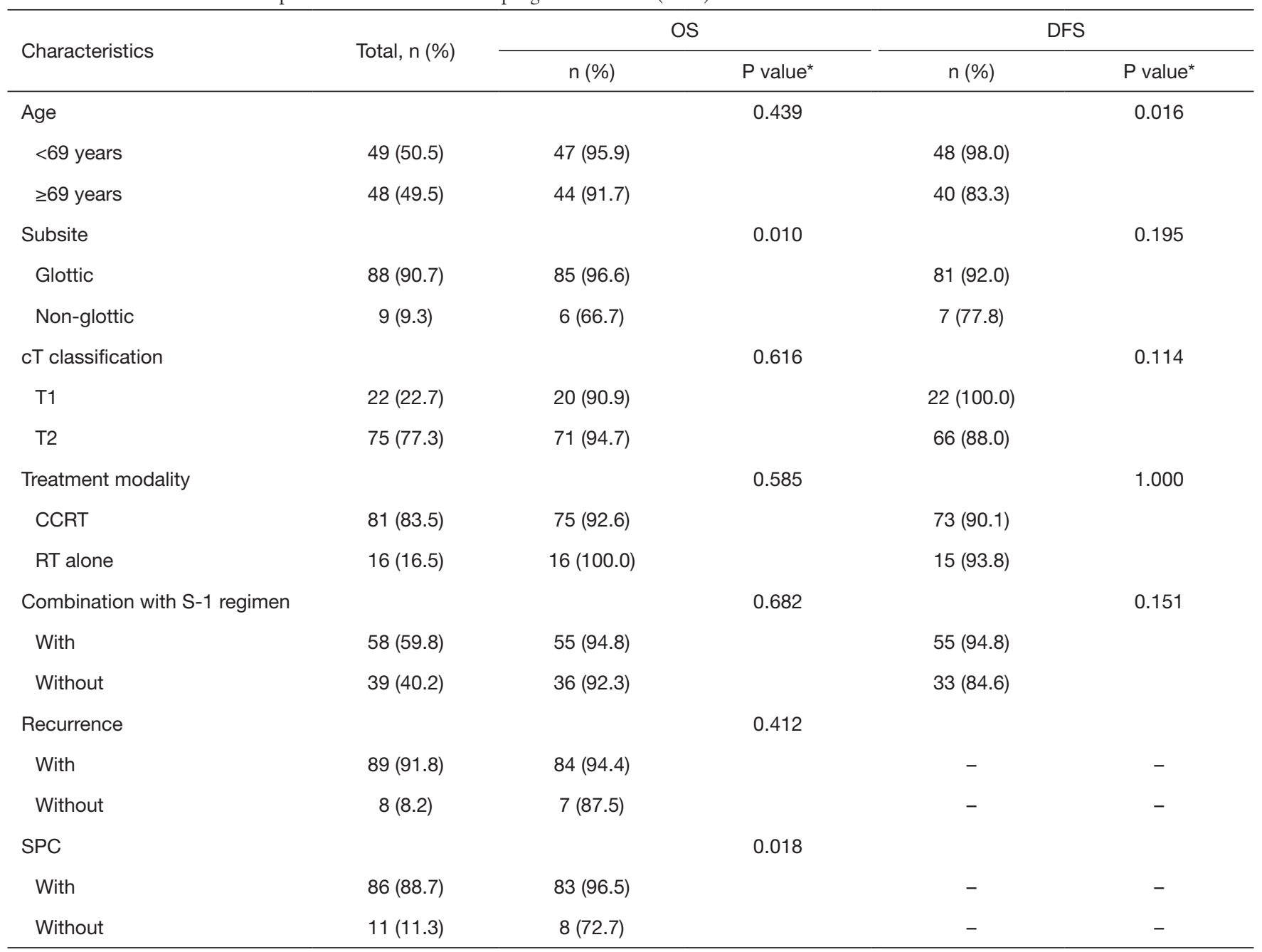

*, Fisher's exact test. OS, overall survival; DFS, disease-free survival; CCRT, concurrent chemoradiotherapy; RT, radiation therapy; S-1, tegafur-gimeracil-oteracil; SPC, second primary cancer.

significant factors were found for the incidence of SPC.

\section{Correlation between the patient characteristics and prognostic factors}

The 5-year OS and DSS for all patients were $91.4 \%$ and $87.0 \%$, respectively. We compared survival outcome by pretreatment factor, treatment modality and combinedagent regimen using univariate and multivariate analysis. The univariate analysis showed that the primary tumor subsite $(\mathrm{P}=0.010)$ and incidence of SPC $(\mathrm{P}=0.018)$ were significant factors for OS, while concurrent chemotherapy or combination with S-1 regimen were not significant factors (Table 5). Multivariate analysis, including age at treatment, primary tumor subsite, $\mathrm{T}$ classification, concurrent chemotherapy, and incidence of SPC, showed that only the primary tumor subsite (hazard ratio $=9.80$; 95\% CI: $1.96-49.10 ; \mathrm{P}=0.006)$ was an independent prognostic factor for OS (Table 6). The Kaplan-Meier curves for subsite, SPC and treatment modality are presented in Figure 1A,B,C, respectively. The 5 -year OS rates for patients with glottic cancer $v s$. non-glottic cancer, patients with SPC vs. those without SPC, and patients treated with $\mathrm{RT}$ alone versus those with CCRT were $97.0 \%$ vs. $70.0 \%(\mathrm{P}<0.001$ : Figure $1 A), 95.2 \%$ vs. 88.9\% $(\mathrm{P}=0.089$ : Figure $1 B)$ and $100 \%$ vs. $93.7 \%(\mathrm{P}=0.572$ : Figure $1 C$ ), respectively. These results indicated that, in patients with ELSCC, non-glottic cancer predicted a 
poorer prognosis, and the incidence of SPC might affect prognosis.

Table 6 Multivariate analyses of clinical factors relating to OS in patients with ELSCC (n=97)

\begin{tabular}{lccc}
\hline \multirow{2}{*}{ Variable } & \multicolumn{3}{c}{ OS } \\
\cline { 2 - 4 } & $\mathrm{HR}$ & $95 \% \mathrm{Cl}$ & $\mathrm{P}$ value \\
\hline Glottic & 1.00 & - & - \\
Non glottic & 9.80 & $1.96-49.1$ & 0.006 \\
\hline
\end{tabular}

*, Cox proportional hazards model. OS, overall survival; ELSCC, early-stage laryngeal squamous cell carcinoma; HR, hazard ratio; $\mathrm{Cl}$, confidence interval.
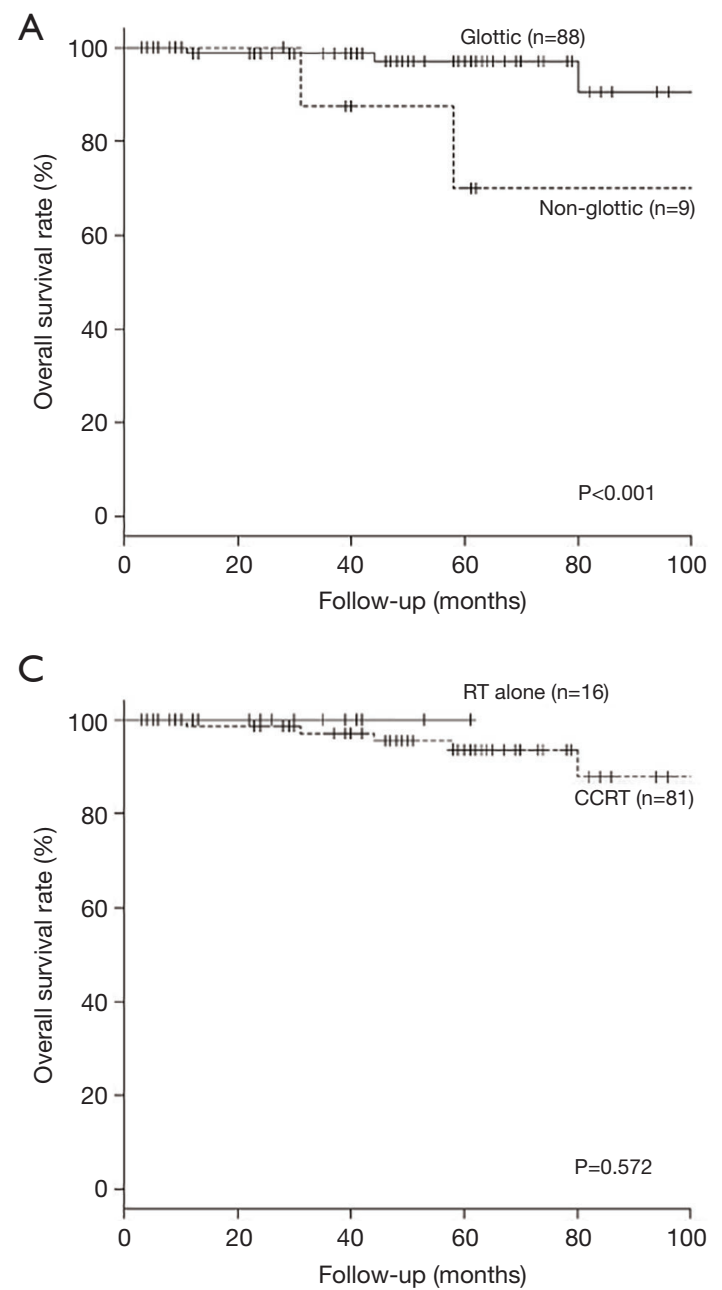

\section{The efficacy of S-1 for CCRT in patients with stage II cancer}

We also analyzed the efficacy of the S-1 regimen in terms of the response to irradiation among the stage II subgroup. Among the patients treated by CCRT with S-1, three had recurrent disease and one died of disease, with three patients who remained recurrence free dying of other disease. Among the patients treated by other treatment methods, six had recurrent disease and were successfully salvaged by surgical treatment, and one recurrence-free patient died of other disease. Next, we compared survival outcome by age, subsite, and combination with S-1 regimen using multivariate analysis. The results showed that only combination with $\mathrm{S}-1$ regimen was an independent

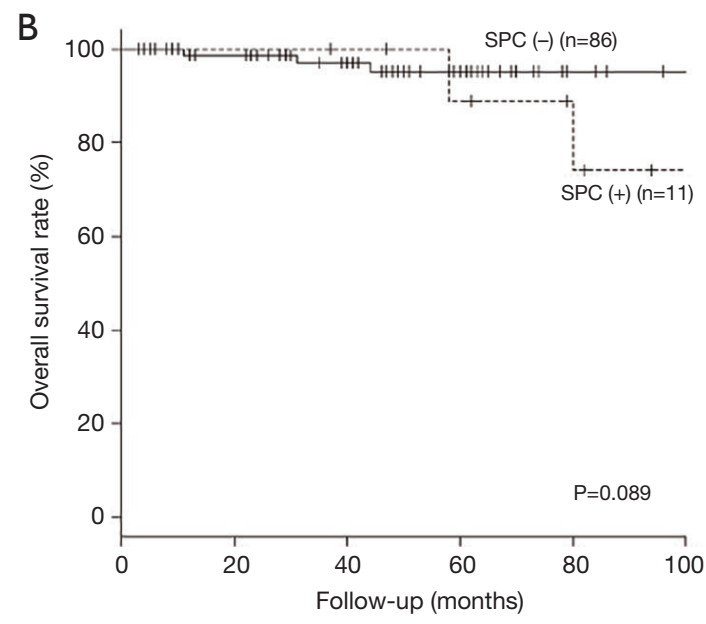

Figure 1 Overall survival rates according to primary tumor subsite (A), second primary cancer (B), and concurrent chemotherapy (C) calculated by the Kaplan-Meier method. 
Table 7 Multivariate analyses of clinical factors relating to DFS in patients with stage II cancer treated with CCRT with S-1 ( $\mathrm{n}=75)$

\begin{tabular}{lccc}
\hline \multirow{2}{*}{ Variable } & \multicolumn{3}{c}{ DFS } \\
\cline { 2 - 4 } & $\mathrm{HR}$ & $95 \% \mathrm{Cl}$ & P value $^{*}$ \\
\hline Combination with S-1 regimen & 1.00 & - & - \\
Combination without S-1 regimen & 5.55 & $1.38-22.2$ & 0.015 \\
\hline
\end{tabular}

*, Cox proportional hazards model. DFS, disease-free survival; CCRT, concurrent chemoradiotherapy; HR, hazard ratio; $\mathrm{Cl}$, confidence; S-1, tegafur-gimeracil-oteracil.

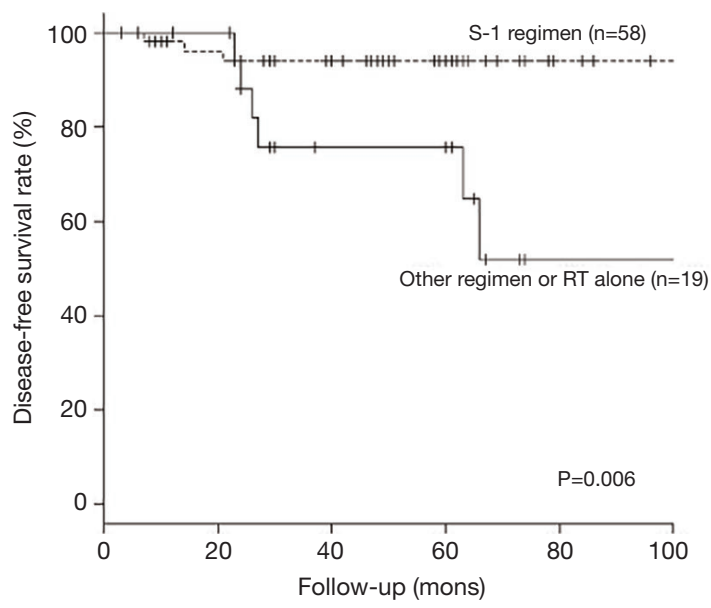

Figure 2 Disease-free survival rates in patients with stage II cancer according to combination with S-1 regimen and the other types of therapy calculated by the Kaplan-Meier method. RT, radiation therapy.

prognostic factor for DFS (hazard ratio $=5.55 ; 95 \%$ CI: 1.38-22.20; $\mathrm{P}=0.015$, Table 7). The Kaplan-Meier curve for combination with S-1 regimen is shown in Figure 2. The 5 -year DFS rates were $94.0 \%$ vs. $75.6 \%(\mathrm{P}=0.006$ : Figure 2). These results indicated that the patients with stage II cancer treated by CCRT in combination with the S-1 regimen showed a better prognosis.

\section{Discussion}

In order to preserve laryngeal function, radiation-based therapy has been used widely for patients with ELSCC. We retrospectively evaluated the efficacy of concurrent chemotherapy and analyzed the prognostic factors in ELSCC patients treated by radiation-based therapy. Our findings indicated that non-glottic subsite and incidence of SPC were poor prognostic factors for radiation-based therapy for ELSCC, and the application of the S-1 regimen improved locoregional control in patients with stage II ELSCC.

In this study, many patients were treated by CCRT in order to improve local control. No patients had any serious adverse events, apart from one patient treated by CCRT with high-intensity chemotherapy (PFML regimen), which indicated that most treatments were completed safely. All patients achieved a CR and the prognosis, other than for the six patients who died, was good. Nine patients who showed recurrence, except one patient, also had a good prognosis by salvage surgery.

The analysis of poor prognostic factors revealed that non-glottic subsite and incidence of SPC affected prognosis adversely. Multiple primary cancers occurred in 38 patients, among whom 11 experienced SPC. All of these 11 patients developed stage II ELSCC and were treated by CCRT. SPC was the cause of death in four of the six patients who died in the present study cohort. Three of the nine patients with non-glottic cancer died, with SPC the cause of death in two.

Supraglottic cancer occasionally leads to cervical lymph node metastasis (3), and subglottic cancer has the potential for distant metastasis $(11,31)$. The 5 -year OS rates were reported to be $49.0-77.0 \%$ for early-stage supraglottic cancer and $45.7 \%$ for early-stage subglottic cancer. Previous articles reported that early-stage non-glottic cancer had a poor prognosis, suggesting that high-intensity treatment methods, such as organ preservation surgery plus neck dissection and surgery with adjuvant radiotherapy, were valid treatment modalities $(10,11)$.

In this study, however, it is difficult to confirm whether or not the prognosis for patients with early-stage nonglottic cancer was poor or whether the treatment method used for them was underpowered. This is due to the fact that many cases of recurrent disease were controlled by salvage surgery, and the cause of a large proportion of deaths was SPC. At the moment, we cannot clarify why many patients with early-stage non-glottic cancer died of SPC; thus, further study is required to determine whether or not there is a correlation.

In patients with HNSCC, the incidence of SPC was considered to be an important issue $(24,26)$. The etiology of SPC is usually explained by the concept of field cancerization (32). Physical and chemical substances, such as smoking and alcohol consumption, pass through and stimulate organs covered with a mucosal epithelium. Consequently, SPC was usually observed in the head and neck, upper gastrointestinal, and respiratory regions (25). 
Notably, second primary lung cancer, head and neck cancer, and esophageal cancer were often significant prognostic factors (26,33). In animal experimental models, the chemoprevention of cancer in the upper respiratory tract was indicated (34).

In this study, SPC was the cause of two-thirds of all deaths, and all of the patients who developed SPC were treated with concurrent chemotherapy. The incidence of SPC affected prognosis as reported previously (35), whereas no significant chemoprevention against SPC by concurrent chemotherapy was shown in this study cohort.

As a chemotherapeutic regimen combined with CCRT, the $\mathrm{S}-1$ regimen was used the most frequently in this study. S-1 is an oral anticancer agent comprising tegafur, gimeracil and oteracil potassium, and has pharmacokinetic properties resembling those of a continuous intravenous infusion of 5 -FU $(16,17)$. Some phase III trials reported that S-1 was a useful anticancer agent for the treatment of other solid cancers, such as gastric cancer, colon cancer, non-small cell lung cancer, breast cancer, and pancreatic cancer (18-22). CCRT in combination with S-1 resulted in a positive outcome in this study. The 56 patients with stage II cancer treated by CCRT with S-1 achieved a CR, with a 5 -year DFS rate of $94.0 \%$. Several articles reported that CCRT with S-1 for the patients with stage II glottic cancer provided good results, with a CR in all patients, 3 -year local control rates of $94.7-95.4 \%$ and 3 -year OS rates of $85.4-100 \%(12-15)$. They also reported that grade 3 mucositis were observed in $3.8-56.5 \%$ of all patients during treatment, whereas no grade 4 adverse events were observed, suggesting CCRT with S-1 is a safe treatment method (12-15). In the present analysis of CCRT with S-1 for patients with stage II ELSCC, the outcomes were comparable to those of previous articles $(9,12-15)$, suggesting that CCRT with $\mathrm{S}-1$ regimen is a safe and effective treatment strategy for stage II ELSCC.

There are several limitations to this study, including its single-institution setting, uneven treatment method, uneven CCRT regimen, and small number of deaths. However, the present study remains of importance as it represents the largest series of stage II ELSCC patients treated with CCRT with S-1 reported to date.

\section{Conclusions}

In conclusion, the results of this study suggested that earlystage non-glottic subsite and incidence of SPC were poor prognostic factors for radiation-based therapy for ELSCC, and CCRT with S-1 was a useful treatment strategy for patients with stage II ELSCC. Future prospective studies are required to validate the treatment methods for nonglottic cancer, establish early detection and treatment methods for SPC, and determine whether CCRT with S-1 improves the prognosis.

\section{Acknowledgments}

Funding: This study was funded by a Grant-in-Aid for Scientific Research (C) (grant number KAKENHI17K11395) from the Japan Society for the Promotion of Science (JSPS).

\section{Footnote}

Conflicts of Interest: TAll authors have completed the ICMJE uniform disclosure form (available at http://dx.doi. org/10.21037/tcr.2018.06.15). The authors have no conflicts of interest to declare.

Ethical Statement: The authors are accountable for all aspects of the work in ensuring that questions related to the accuracy or integrity of any part of the work are appropriately investigated and resolved. All procedures performed in studies involving human participants were in accordance with the ethical standards of the institutional and/or national research committee and with the 1964 Helsinki declaration and its later amendments or comparable ethical standards. A written informed consent was obtained for all participants of the study. This study was approved by the International Review Board of Yokohama City University Hospital.

Open Access Statement: This is an Open Access article distributed in accordance with the Creative Commons Attribution-NonCommercial-NoDerivs 4.0 International License (CC BY-NC-ND 4.0), which permits the noncommercial replication and distribution of the article with the strict proviso that no changes or edits are made and the original work is properly cited (including links to both the formal publication through the relevant DOI and the license). See: https://creativecommons.org/licenses/by-nc-nd/4.0/.

\section{References}

1. Warner L, Chudasama J, Kelly CG Y, et al. Radiotherapy versus open surgery versus endolaryngeal surgery (with or without laser) for early laryngeal 
squamous cell cancer. Cochrane Database Syst Rev 2014;12:CD002027.

2. Kotwall C, Sako K, Razack MS, et al. Metastatic patterns in squamous cell cancer of the head and neck. Am J Surg 1987;154:439-42.

3. NCCN practice guidelines in oncology: Head and Neck Cancer, v.2, 2016. Available online: http://www.nccn.org

4. Feng $\mathrm{Y}$, Wang B, Wen $\mathrm{S}$. Laser surgery versus radiotherapy for T1-T2N0 glottic cancer: a meta-analysis. ORL J Otorhinolaryngol Relat Spec 2011;73:336-42.

5. Valls-Mateus M, Ortega A, Blanch JL, et al. Longterm quality of life after transoral laser microsurgery for laryngeal carcinoma. J Surg Oncol 2016;114:789-95.

6. Aaltonen LM, Rautiainen N, Sellman J, et al. Voice quality after treatment of early vocal cord cancer: a randomized trial comparing laser surgery with radiation therapy. Int J Radiat Oncol Biol Phys 2014;90:255-60.

7. Higgins KM, Shah MD, Ogaick MJ, et al. Treatment of early-stage glottic cancer: meta-analysis comparison of laser excision versus radiotherapy. J Otolaryngol Head Neck Surg 2009;38:603-12.

8. Cellai E, Frata P, Magrini SM, et al. Radical radiotherapy for early glottic cancer: Results in a series of 1087 patients from two Italian radiation oncology centers. I. The case of T1N0 disease. Int J Radiat Oncol Biol Phys 2005;63:1378-86.

9. Frata P, Cellai E, Magrini SM, et al. Radical radiotherapy for early glottic cancer: Results in a series of 1087 patients from two Italian radiation oncology centers. II. The case of T2N0 disease. Int J Radiat Oncol Biol Phys 2005;63:1387-94.

10. Arshad H, Jayaprakash V, Gupta V, et al. Survival differences between organ preservation surgery and definitive radiotherapy in early supraglottic squamous cell carcinoma. Otolaryngol Head Neck Surg 2014;150:237-44.

11. Marchiano E, Patel DM, Patel TD, et al. Subglottic Squamous Cell Carcinoma: A Population-Based Study of 889 Cases. Otolaryngol Head Neck Surg 2016;154:315-21.

12. Taguchi T, Takahashi M, Nishimura G, et al. Phase II study of concurrent chemoradiotherapy with S-1 in patients with stage II (T2N0M0) squamous cell carcinoma of the Pharynx or Larynx. Jpn J Clin Oncol 2014;44:1158-63.

13. Nakayama M, Hayakawa K, Okamoto M, et al. Phase I/II trial of concurrent use of S-1 and radiation therapy for T2 glottic cancer. Jpn J Clin Oncol 2010;40:921-6.

14. Nishimura G, Tsukuda M, Mikami Y, et al. Efficacy of concurrent chemoradiotherapy for $\mathrm{T} 1$ and $\mathrm{T} 2$ laryngeal squamous cell carcinoma regarding organ preservation. Anticancer Res 2009;29:661-6.

15. Nonoshita T, Shioyama Y, Nakamura K, et al. Concurrent chemoradiotherapy with S-1 for T2N0 glottic squamous cell carcinoma. J Radiat Res 2010;51:481-4.

16. Shirasaka T, Nakano K, Takechi T, et al. Antitumor activity of $1 \mathrm{M}$ tegafur-0.4 M 5-chloro-2,4dihydroxypyridine- $1 \mathrm{M}$ potassium oxonate (S-1) against human colon carcinoma orthotopically implanted into nude rats. Cancer Res 1996;56:2602-6.

17. Schöffski P. The modulated oral fluoropyrimidine prodrug $\mathrm{S}-1$, and its use in gastrointestinal cancer and other solid tumors. Anticancer Drugs 2004;15:85-106.

18. Koizumi W, Narahara H, Hara T, et al. S-1 plus cisplatin versus $\mathrm{S}-1$ alone for first-line treatment of advanced gastric cancer (SPIRITS trial): a phase III trial. Lancet Oncol 2008;9:215-21.

19. Yoshida $M$, Ishiguro $M$, Ikejiri $\mathrm{K}$, et al. S-1 as adjuvant chemotherapy for stage III colon cancer: a randomized phase III study (ACTS-CC trial). Ann Oncol 2014;25:1743-9.

20. Kubota K, Sakai H, Katakami N, et al. A randomized phase III trial of oral S-1 plus cisplatin versus docetaxel plus cisplatin in Japanese patients with advanced nonsmall-cell lung cancer: TCOG0701 CATS trial. Ann Oncol 2015;26:1401-8.

21. Takashima T, Mukai H, Hara F, et al. Taxanes versus S-1 as the first-line chemotherapy for metastatic breast cancer (SELECT BC): an open-label, non-inferiority, randomised phase 3 trial. Lancet Oncol 2016;17:90-8.

22. Ueno H, Ioka T, Ikeda M, et al. Randomized phase III study of gemcitabine plus S-1, S-1 alone, or gemcitabine alone in patients with locally advanced and metastatic pancreatic cancer in Japan and Taiwan: GEST study. J Clin Oncol 2013;31:1640-8.

23. León X, Quer M, Diez S, et al. Second neoplasm in patients with head and neck cancer. Head Neck 1999:21:204-10.

24. Tiwana MS, Hay J, Wu J, et al. Incidence of second metachronous head and neck cancers: population-based outcomes over 25 years. Laryngoscope 2014;124:2287-91.

25. Atienza JA, Dasanu CA. Incidence of second primary malignancies in patients with treated head and neck cancer: a comprehensive review of literature. Curr Med Res Opin 2012;28:1899-909.

26. Haughey BH, Gates GA, Arfken CL, et al. Meta-analysis of second malignant tumors in head and neck cancer: 
the case for an endoscopic screening protocol. Ann Otol Rhinol Laryngol 1992;101:105-12.

27. Kodaira T, Fuwa N, Furutani K, et al. Phase I trial of weekly docetaxel and concurrent radiotherapy for head and neck cancer in elderly patients or patients with complications. Jpn J Clin Oncol 2005;35:173-6.

28. Bonner JA, Harari PM, Giralt J, et al. Radiotherapy plus cetuximab for squamous-cell carcinoma of the head and neck. N Engl J Med 2006;354:567-78.

29. Taguchi T, Nishimura G, Takahashi M, et al. Treatment results and prognostic factors for advanced squamous cell carcinoma of the hypopharynx treated with concurrent chemoradiotherapy. Cancer Chemother Pharmacol 2014;73:1147-54.

30. Eisenhauer EA, Therasse P, Bogaerts J, et al. New response evaluation criteria in solid tumours: revised RECIST guideline (version 1.1). Eur J Cancer

Cite this article as: Sato K, Yabuki K, Sano D, Arai Y, Chiba Y, Tanabe T, Nishimura G, Hata M, Oridate N. Analysis of prognostic factors, including the incidence of second primary cancer, in patients with early stage laryngeal squamous cell carcinoma treated by radiation-based therapy. Transl Cancer Res 2018;7(4):890-900. doi: 10.21037/tcr.2018.06.15
2009;45:228-47.

31. Garas J, McGuirt WF Sr. Squamous cell carcinoma of the subglottis. Am J Otolaryngol 2006;27:1-4.

32. Slaughter DP, Southwick HW, Smejkal W. "Field cancerization" in oral stratified squamous epithelium. Cancer 1953;6:963-8.

33. Gao X, Fisher SG, Mohideen N, et al. Second primary cancers in patients with laryngeal cancer: a populationbased study. Int J Radiat Oncol Biol Phys 2003;56:427-35.

34. Wattenberg LW, Wiedmann TS, Estensen RD. Chemoprevention of cancer of the upper respiratory tract of the Syrian golden hamster by aerosol administration of difluoromethylornithine and 5-fluorouracil. Cancer Res 2004;64:2347-9.

35. Chen MC, Huang WC, Chan CH, et al. Impact of second primary esophageal or lung cancer on survival of patients with head and neck cancer. Oral Oncol 2010;46:249-54. 